\title{
Why Can't They Keep the Book Longer and Do We Really Need to Charge Fines? Assessing Circulation Policies at the Harold B. Lee Library: A Case Study
}

Duane E Wilson

duane_wilson@byu.edu

Follow this and additional works at: https://scholarsarchive.byu.edu/facpub

Part of the Library and Information Science Commons

\section{Original Publication Citation}

Duane Wilson. Why Can't They Keep the Book Longer and Do We Really Need to Charge Fines? Assessing Circulation Policies at the Harold B. Lee Library: A Case Study. Journal of Access Service. Volume 11, Issue 3, Pages 135-149.

\section{BYU ScholarsArchive Citation}

Wilson, Duane E, "Why Can't They Keep the Book Longer and Do We Really Need to Charge Fines? Assessing Circulation Policies at the Harold B. Lee Library: A Case Study" (2014). Faculty Publications. 1598.

https://scholarsarchive.byu.edu/facpub/1598

This Peer-Reviewed Article is brought to you for free and open access by BYU ScholarsArchive. It has been accepted for inclusion in Faculty Publications by an authorized administrator of BYU ScholarsArchive. For more information, please contact ellen_amatangelo@byu.edu. 
Title: Why can't they keep the book longer and do we really need to charge fines? Assessing circulation policies at the Harold B. Lee Library: A Case Study

\begin{abstract}
In response to a charge from the library administration, the Circulation Committee of the Harold B. Lee Library at Brigham Young University designed and implemented a thorough assessment of circulation policies. Using multiple assessment methods including surveys, focus groups, and statistical analysis, the committee determined that the undergraduate checkout period was not sufficient and that the fine structure needed to change. Using the information obtained through the assessment they were able to successfully lobby for an extension to the undergraduate checkout period and for the elimination of fines for regular overdue materials.
\end{abstract}

\title{
Introduction
}

Brigham Young University (BYU) is a research university with approximately 30,000 students. The Harold B. Lee Library is a member of the Association of Research Libraries (ARL) and serves the entire campus with over four million books and an annual circulation of around 400,000 volumes.

As a result of concerns from library staff and administration and in response to comments from library patrons, in spring 2012 the reconstituted circulation committee at the Lee Library was charged with reviewing existing circulation policies. Staff and patrons were primarily concerned with the length of the checkout period in combination with the number of unseen renewals (the ability to renew an item without bringing it in to the library) for our patrons: was it sufficient or did some adjustment need to be made? There had also been concerns about our high fines and whether or not they were fulfilling their intended purpose which was to get books back. There had also been many concerns expressed by faculty members over recalls.

In order to discover whether or not these were real concerns and determine the best course of action, the committee decided to conduct a thorough assessment of the Lee Library's policies. The 
committee chose a multi-pronged assessment approach with the goal of triangulating the results. The idea of triangulation is that, if multiple assessment methods reach the same or similar conclusions, then those conclusions are more likely to be valid than conclusions reached through only one method.

The methods the committee chose were surveys, focus groups, and an analysis of local checkout statistics. The committee felt that these three methods would give a good mix of quantitative and qualitative data and would provide a variety of perspectives.

\section{Surveys}

The committee chose to administer two surveys. Since a literature search did not yield data on the circulation policies of libraries similar to the Lee Library, the purpose of the first survey was to examine the policies of similar libraries for benchmarking purposes. The second survey was designed to gather the opinions and attitudes of Lee Library patrons about current library policies. To create the surveys the committee brainstormed what information was needed to make an informed decision. Knowing that the wording would greatly affect how people perceived the questions, the committee carefully considered the wording of each question. The committee drafted the survey using the Qualtrics survey tool. After finalizing the questions, the surveys received approval from BYU's Institutional Review Board (IRB) (see appendix for final text of surveys).

For the survey of other libraries, the committee chose a sampling of libraries at institutions with a campus population similar to that of BYU so that comparisons would be more meaningful. Because the Lee Library is a member of ARL, the committee chose ARL libraries as an initial sample. The committee then used the library comparison tool provided by the National Center for Educational Statistics (NCES) to find additional institutions with libraries similar to BYU's Lee Library. The committee chose institutions that offer at least a bachelor's degree and had mid to high enrollments (16,000-60,000 FTE). The combination of ARL libraries and libraries selected through the NCES tool yielded a total of 167 libraries to be surveyed. After the committee selected the institutions, it identified circulation or access 
services department heads or their equivalent at the institutions' libraries and emailed the survey directly to them using the distribution tools that are part of Qualtrics.

For the local patron survey, the committee extracted lists of undergraduate, graduate, and faculty patrons from the Lee Library's local library system. With the help of the library's statistical specialist, the committee took a statistically significant sampling from these lists. The committee then used the Qualtrics survey tool to send an initial email invitation to the sampled groups, along with two follow-up email messages. The committee learned from the Lee Library Assessment Team that the campus community usually responds well to surveys. As a result, the committee chose not to provide an incentive to encourage survey participation. The number of survey respondents was statistically significant despite the lack of incentive.

Once the committee completed the data gathering from the surveys, it had the library's statistical specialist help analyze the responses. From the survey of other libraries the committee found that the majority of libraries had a longer undergraduate checkout period and lower fines than the Lee Library. It also found that libraries that had eliminated fines were very pleased with the positive effects of this change and that most libraries had the same types of problems with patrons being frustrated about the early return of their books because of a recall.

From the patron survey the committee found that undergraduate students felt that they needed books longer than their checkout period currently allowed, while graduate students, staff, and faculty members felt that their checkout lengths were sufficient. Patrons from all of the surveyed groups shared many concerns surrounding fines and how they were implemented. In addition, patrons had many questions and concerns about the recall system, especially faculty patrons. We found that renewals were only an issue in combination with the circulation period - patrons were not concerned with the number of renewals if their checkout period was long enough.

\section{Focus Groups}


Knowing that quantitative data is only part of the story, and to get a variety of perspectives, the committee decided to hold multiple focus groups with different constituents. The following groups were selected because they represented the majority of stakeholders in the discussion of circulation policies: undergraduate students, graduate students, library subject specialists, library help desk staff, access services employees, and student workers at help desks.

The committee chose to wait until after the surveys were analyzed to determine what additional information was needed to better understand patron and employee opinions of library policies. Committee members then carefully crafted and reviewed the focus group questions in response to the survey analysis, creating a separate set of questions for internal and external patrons. After the committee completed the questions they were submitted to the IRB office for approval (see appendix for focus group questions). Because with human subjects were involved in the groups, a consent form was required. The committee developed their own consent form after reviewing the items that the IRB office required (see appendix for consent form).

The Lee Library samples without replacement, meaning that anyone who is asked to take a library survey or participate in a focus group will not be asked to participate again in the same semester. Though this means that the survey sampling is not truly random, the survey results are still statistically significant and the possibility of survey fatigue is reduced.

In order to recruit participants for undergraduate and graduate student focus groups, the committee again selected a sampling of names from the library system. Students were emailed the date and time of the focus group with a request for an RSVP. The committee provided pizza as an incentive, advertising this in recruitment efforts. The library employee groups were much more motivated and easy to recruit than were external patrons. To recruit these employee groups the committee simply emailed the library subject specialists, help desk staff employees, and access services groups asking them to participate. The committee discussed the student worker focus group with their supervisors and asked the supervisors to encourage volunteers. 
The library usability lab was used to record video and audio of focus group sessions.

Unfortunately, the recording software malfunctioned in several focus groups and the committee was left with summaries of the groups rather than full transcripts. That being said, the summaries were helpful and provided the needed information. In the case of the original undergraduate focus group, there was not enough participation so the committee expanded recruiting efforts and held the focus group again with a different set of participants. The library assessment personnel, who have experience leading focus groups, acted as moderators for the groups.

The assessment personnel also provided transcripts of the focus groups for analysis. After receiving the transcripts and/or summaries, the committee carefully read and reviewed the data, looking for trends. The focus groups revealed that the undergraduate checkout period was not sufficient, that fine implementation was problematic, that fines were higher than necessary, and that recalls caused considerable concern for faculty patrons.

\section{Statistics}

In order to get more facts about actual checkout behavior, the committee examined statistical data for the time period of January 2010-May 2013. The committee analyzed all checkouts recorded during that time according to patron type and length of checkout. As a result of the analysis, committee members found that undergraduates typically kept the books longer than the initial 21 day checkout period and that they tended to renew their books at least once. In contrast, graduate students, faculty, and staff tended to return their books before the initial checkout period was completed. The committee also found that all patrons tended to return books on or before the due date.

\section{Facilitating Change}

As mentioned before, the committee felt that triangulating results would provide a more valid basis on which to make decisions. In circulation committee meetings, committee members discussed the surveys, focus groups, and statistics after different members of the committee provided summaries of the 
information. Members then looked for findings that were common among the various methods. The triangulation efforts paid off, showing similar themes between all evaluation methods.

The committee began to share these results widely with important stake holders throughout the library and made specific recommendations to extend the undergraduate checkout period and eliminate regular overdue fines in the library. The committee decided to address recalls through an automated system that would determine when and how to route requests through holds or inter-library loan. This system is already under development and will provide better service and help the library eliminate the majority of recalls. As the committee discussed its findings in various library venues, it listened for problems and concerns from library staff members and responded accordingly. One department was concerned that increasing the circulation period of items in their subject would make books less available to patrons who needed them for specific classes. The committee analyzed the circulation of this collection and showed that an increased circulation period would have minimal effect on the patrons.

After the committee's discussions, the committee chair created a summary report detailing the committee's findings and describing its recommendations. As described above, the committee's results supported three main findings: that undergraduate checkout periods were not long enough, that fines were problematic in their function and execution, and that there were many problems and concerns about recall policies. To respond to these findings the committee recommended an extension of the undergraduate checkout period from three weeks to six. It determined that, since there were other methods to incentivize the return of library materials, the best way to resolve the issues with regular overdue fines was to eliminate them for all except community patrons. The committee determined to use a new technology solution being developed by the library's information technology group to eliminate the majority of overdue fines. This formal report was discussed in applicable library committees and shared with library employees. Since the findings and possible recommendations had been shared widely throughout the library prior to the report being written, most concerns had already been addressed and the changes to library policy were approved by library administration. 


\section{Conclusion}

The committee set out with the purpose of understanding exactly what problems the library was having in relation to circulation policies, including the length of checkout, fines, and renewals, and determining ways to fix them. The assessment methods the committee pursued provided abundant data that in some cases confirmed suspicions and in other cases eliminated concerns. The committee was able to determine exactly what things needed to be changed and were able to find ideas for possible solutions. For example, in the case of fines it was discovered that the only reason for a fine is to incentivize the return of library materials. Because of high fines and the inconsistent way in which they were administered, the fines caused more confusion and problems for the patron than was necessary. Since the library has other ways to incentivize the return of books, the committee decided that regular fines did not serve any useful purpose and will be eliminated. Without discovering the problem through assessment and also examining possible solutions through literature review and study of other schools, the committee would not have been able to justify the need for these changes.

As mentioned earlier, triangulation is one of the best methods to help make sure that assessments are valid. In this particular case, triangulation was a very powerful way of showing that there were problems for which solutions were needed. Since all of the methods supported the committee's major findings, it was much easier to convince others that changes needed to be made.

A great deal of patience and perseverance was required as a result of the lengthy process. The committee began discussing the assessment in May 2012. The surveys were administered in November 2012 and the focus groups were held at the beginning of 2013. The internal report was completed at the end of summer 2013 and the findings were discussed in the library during fall 2013. The extended circulation period was implemented at the beginning of 2014 and comments about the change from patrons have been very positive. In addition, regular overdue fines will be eliminated at the end of Winter Semester 2014. The ability to persist and create positive change, despite the lengthy process, made the assessments well worth the effort. 
Overall the study and the use of multiple assessment methods was very effective way to discover and implement useful change. The committee will soon be assessing the changes that were made to evaluate their efficacy and impact.

\section{Appendix:}

\section{Circulation in Libraries Survey}

This survey is being conducted by the Circulation Committee at the Brigham Young University Harold B. Lee Library to explore circulation procedures at other libraries. This survey should take 5-10 minutes to complete. Involvement in this survey is voluntary. You may withdraw at any time or refuse to participate entirely without penalty. There are minimal risks to your participation in this study. The findings may be presented and published to the professional library community. No information that could link you to your answers will be collected or maintained. There will be no reference to your identification at any point during the analysis or reporting of the results. By proceeding to the next page, you consent to participate in this study. If you have any questions regarding this study you may contact Duane Wilson at (801) 422-9144.

1. What is the standard circulation period for the following patron types when checking out a book from the main collection? If you do not have one of these patron types, please leave the box empty.

Undergraduate Student (1)

Graduate Student (2)

Staff (3)

Faculty (4)

Community (5)

2. Comments about circulation periods?

3. How many times can a patron renew before they have to bring the book into the library? If you do not have one of these patron types, please leave the slider at 0 .

Undergraduate Student (1)

Graduate Student (2)

Staff (3)

Faculty (4)

Community (5)

4. Comments about renewals?

5. Does your library charge overdue fines?

O Yes (1)

We used to. (2)

We have never charged fines. (3) 
Answer If Does your library charge overdue fines? We used to. Is Selected Or Does your library charge overdue fines? We have never charged fines. Is Selected

6. How does your library encourage patrons to return their library items? Check all that apply.

Bill for unreturned books (1)

B Block library privileges (2)

B Block university privileges (3)

B Block registration for class (4)

B Block graduation (5)

$\square$ Other (6)

Answer If Does your library charge overdue fines? We used to. Is Selected

7. What changes has your library experienced as a result of not charging overdue fines?

We have more problems with patrons returning their books (1)

We have about the same number of problems with patrons returning their books (2)

O We have fewer problems with patrons returning their books (3)

Answer If Does your library charge overdue fines? We used to. Is Selected

8. What additional changes has your library experienced as a result of not charging overdue fines?

9. Comments about whether or not your library should fine patrons?

Answer If Does your institution charge fines for books that are ret... Yes Is Selected

10. What is the standard overdue daily fine for a book? Please exclude special items.

O $\$ 0.01-\$ 0.25(1)$

O $\$ 0.26-\$ 0.50(2)$

O $\$ 0.51-\$ 1.00(3)$

O $\$ 1.01-\$ 5.00(4)$

More than $\$ 5.00(5)$

Answer If Does your institution charge fines for books that are ret... Yes Is Selected

11. What is the standard maximum overdue fine for a book? Please exclude special items.

O $\$ 0.01-\$ 5.00(1)$

O $\$ 5.01-\$ 10.00(2)$

O $\$ 10.01-\$ 15.00(3)$

O $\$ 15.01-\$ 20.00(4)$

O $\$ 20.01-\$ 50.00$ (5)

O more than $\$ 50.00$ (6) 
Answer If Does your institution charge fines for books that are ret... Yes Is Selected

12. In your opinion, do fines encourage your patrons to return their books on time?

O Yes (1)

O No (2)

I don't know. (3)

13. In your opinion, do you think that fines do the following? Please select all that apply.

Help get materials back (1)

Discourage use of the library (2)

Don't do any good (3)

$\square$ Other (4)

14. Comments about library fines?

15. What does your library do when a patron wants an item that is checked out? Check all that apply.

$\square$ Recall the item. (1)

Interlibrary loan a copy of the item. (2)

- Purchase an additional copy of the item. (3)

The patron has to wait until the item is returned. (4)

$\square$ Other (5)

Answer If What does your library do when a patron wants an item tha... Recall the item. Is Selected

16. Please mark all of the reasons why your library would recall an item:

A professor wants to place the item on reserve. (1)

Another patron needs the item. (2)

$\square$ Other (3)

Answer If What does your library do when a patron wants an item tha... Recall the item. Is Selected 17. How long can a patron keep an item after it has been recalled?

Until the end of their current circulation period (1)

Within just a few days after the recall (2)

Other (3)

Answer If What does your library do when a patron wants an item tha... Recall the item. Is Selected

18. Are you happy with the current recall system in your library

O Yes (1)

No (2) 
Answer If What does your library do when a patron wants an item tha... Recall the item. Is Selected 19. Comments about recalls? 


\section{BYU Patron Circulation Survey}

This survey is being conducted by the Circulation Committee at the Brigham Young University Harold B. Lee Library to examine the opinions of library patrons relating to library checkout, fines and related policies. This survey should take approximately 10 minutes to complete. Involvement in this survey is voluntary. You may withdraw at any time or refuse to participate entirely without penalty. There are minimal risks to your participation in this study. The findings may be presented and published to the professional library community. No information that could link you to your answers will be collected or maintained. There will be no reference to your identification at any point during the analysis or reporting of the results. By proceeding to the next page, you consent to participate in this study. If you have any questions regarding this study you may contact Duane Wilson at (801) 422-9144.

1. Please choose the description that best fits you.

Undergraduate Student (1)

O Graduate Student (2)

O Faculty (3)

Administrative (4)

Staff (5)

2. Have you ever checked out anything from the library?

O Yes (1)

No (2)

If Yes Is Selected, Then Skip To When you look for an item in the libr...

Answer If Have you ever checked out anything from the library? No Is Selected

3. Have you ever tried to find an item in the library?

O Yes (1)

O No (2)

If No Is Selected, Then Skip To End of Survey

4. When you look for an item in the library, how frequently is it there?

O Never (1)

Rarely (2)

O Sometimes (3)

O Most of the time (4)

Always (5) 
5. If an item isn't there, what do you normally do? Check all that apply.

A Ask at a library help desk. (1)

Request the item through interlibrary loan. (2)

Find another item in the library. (3)

$\square$ Place a hold on the item. (4)

- Find the item at a local public library. (5)

a Purchase the item. (6)

$\square$ Other (7)

6. When you check out a book or music score, how long do you usually need it?

(1)

7. Comments about checkout length?

8. When you need an item longer, how many times do you usually renew it?

O None (1)

Once (2)

Twice (3)

Three (4)

Four (5)

More than Four (6)

9. Have you ever placed a hold on an item in the library?

Y Yes (1)

O No (2)

Answer If Have you ever placed a hold on an item in the library? Yes Is Selected

10 . When you place a hold, how soon do you usually get the item?

0-2 days (1)

O $3-7$ days (2)

O 7-14 days (3)

14-21 days (4)

O More than 21 days (5) 
Answer If Have you ever placed a hold on an item in the library? Yes Is Selected

11 . When you place a hold, do you usually receive the item in time to meet your needs?

O Yes (1)

O No (2)

Answer If Have you ever placed a hold on an item in the library? Yes Is Selected

12. How satisfied are you with the hold process?

Very Dissatisfied (1)

Dissatisfied (2)

O Neutral (3)

O Satisfied (4)

Very Satisfied (5)

Answer If Have you ever placed a hold on an item in the library? Yes Is Selected

13. Comments about the hold process?

14. Have you ever had a library item recalled1? 1: A recall means you had to return the item early or couldn't renew it.

O Yes (1)

O No (2)

Answer If Have you ever had any library materials (books, dvd, cd, ... Yes Is Selected

15. What percentage of time do recalls affect you as follows? Total should equal 100.

I am finished with the item. (1)

I haven't used the item yet, but I am not inconvenienced. (2)

I quickly finish doing what I need to with the item, return it, and am not inconvenienced. (3) I am using the item and am greatly inconvenienced. (4) I am out of town and unable to return the item. (5)

16. What motivates you to return library materials? Check all that apply.

Making the item available for someone else (1)

B Being finished with the item (2)

$\square$ Due dates (3)

Small fines, such as $\$ 0.10 /$ day (4)

Large fines, such as at $\$ 1 /$ day (5)

- \$10 recall overdue fine (6)

A block on your library account, preventing you from checking out materials (7)

A block on your university account, preventing registration and other university transactions (8)

Being billed for the cost of unreturned items (9)

$\square$ Other (10) 
17. Have you ever had a library fine at the Harold B. Lee Library?

O Yes (1)

No (2)

Answer If Have you ever had a library fine before? Yes Is Selected

18 . When you have fines, how are they typically handled?

O I am required to pay the full amount. (1)

The fine is reduced. (2)

The fine is forgiven. (3)

19. Comments about library fines? 


\section{Questions for Undergraduate and Graduate Student Focus Groups:}

1. We have a variety of policies about check-outs and fines, etc. As a library user, what do you know about these policies?

2. What motivates you to return library materials?

3. What is your experience/opinion with library recalls? (Explain/define recalls if necessary)

4. What is your experience/opinion with library fines?

a. Follow-up: How did that impact your use of the library? (Ask for more details if necessary)

5. When you checkout library materials, how long do you typically need them?

6. The library allows you to renew books. What has been your experience with renewals?

a. Follow-up: Solicit opinions on the number of online renewals needed.

7. If you could change the policies we've discussed in any way, how would you? 


\section{Questions for the Library Staff and Student worker Focus Groups:}

1. What is your understanding of the current policies of the library in relation to checkout periods, holds, recalls, renewals, and fines?

2. How do current policies affect your work? How do current policies affect the library?

3. What do library patrons say about circulation policies?

4. How would changing circulation periods (increasing 3-week student period or staff/faculty periods) affect your work?

5. How would lowering or eliminating fines affect your work?

6. How would increasing the number of unmediated renewals affect your work?

7. How would changing the current recall system affect your work?

8. If you were able to design circulation policies in any way you would like, how would you design them? 


\section{Consent to be a Research Subject}

\section{Introduction}

This research study is being conducted by the circulation committee of the Harold B. Lee Library (Duane Wilson, Jo Ann Larsen, Cynthia Frazier, Diana Harter, Connie Lamb, Ellen Wilson) at Brigham Young University to determine whether or not circulation policies should be modified. You were invited to participate because you are a student worker at the Harold B. Lee Library.

\section{Procedures}

If you agree to participate in this research study, the following will occur:

- you will be invited to participate in a focus group discussing circulation policies and procedures at the HBLL

- you will be placed in a group with other student workers

- the focus group will be audio recorded to ensure accuracy in reporting your statements

- the focus group will be held in the Usability lab in the Harold B. Lee Library

- total time commitment will be sixty (60) minutes

\section{Risks/Discomforts}

There are minimal risks for participation in this study. You may, however, feel some discomfort when answering questions about personal beliefs or when being audio recorded. In focus groups, it is possible that you may feel embarrassed when talking in front of others. If you feel embarrassed about answering a particular question, you may choose to decline or excuse yourself from the study.

\section{Benefits}

There will be no direct benefits to you. It is hoped, however, that through your participation researchers may learn about student worker's opinions about circulation policies and how they might be improved.

\section{Confidentiality}

The research data will be kept on password protected network drives and only the researcher, the principal investigator and the coinvestigators will have access to the data. At the conclusion of the study, all identifying information will be removed and the data will be kept in the principal investigator's locked cabinet.

\section{Compensation}

Those participating in the focus group will be compensated with a pizza or sandwich lunch. Compensation will not be prorated.

\section{Participation}

Participation in this research study is voluntary. You have the right to withdraw at any time or refuse to participate entirely without jeopardy to your class status, grade, or standing with the university.

\section{Questions about the Research}

If you have questions regarding this study, you may contact Duane Wilson at duane_wilson@byu.edu, phone 801-422-9144 for further information.

\section{Questions about Your Rights as Research Participants}

If you have questions regarding your rights as a research participant contact IRB Administrator at (801) 422-1461; A-285 ASB, Brigham Young University, Provo, UT 84602; irb@byu.edu.

\section{Statement of Consent}

I have read, understood, and received a copy of the above consent and desire of my own free will to participate in this study.

Name (Printed): Signature

Date: 